\title{
Foamy Virus of Monkeys
}

\author{
By G. PLUMMER \\ Wellcome Research Laboratories, Beckenham, Kent
}

(Received 26 March 1962)

\begin{abstract}
SUMMARY
Foamy virus has occurred in 40-60\% of vervet, rhesus and cynomolgus monkey kidney tissue cultures, but has been absent from Erythrocebus patas cultures. Factors influencing its passage in tissue culture have been investigated. The virus is sensitive to ether and chloroform. Ultracentrifugation indicated a particle size of greater than $70 \mathrm{~m} \mu$. No haemagglutination or haemadsorption could be demonstrated with erythrocytes from a variety of animals. No reduction in titre resulted from eleven months' storage of a serum-free suspension at $-20^{\circ}$. Stability at other temperatures was determined.
\end{abstract}

\section{INTRODUCTION}

A cytopathic effect, commonly occurring spontaneously in rhesus monkey kidney tissue cultures and characterized by the formation of syncytia which developed a 'foamy' or 'lacey' appearance, was described by Rustigian, Johnston \& Reihart in 1955. Brown (1957) and Ruckle (1958) showed that the foamy cytopathic effect was transmissible in rabbit kidney cultures, Brown also demonstrating that the transmissible agent was filtrable. Ruckle indicated a superficial similarity between the cytopathic effects of the foamy agent and the measles-like MINIA (monkey intranuclear inclusion agent). Johnston (1961) reported the isolation of foamy agent from the throats of monkeys. He also isolated, from Macaca cyclopsis, an agent causing a cytopathic effect in rabbit kidney cultures identical with that of the strains of Rustigian et al. (1955), but which was serologically distinct from these strains. Malherbe \& Harwin (1957) described an agent, termed SA 1, which caused a foamy-type cytopathic effect in kidney cultures from vervet monkeys (Cercopithecus sp.). In 1957 Hull \& Minner stated that their many attempts to subculture foamy agent in monkey kidney tissue cultures had failed; they did not therefore include it in their classification of monkey viruses.

This paper details further properties of this agent and factors influencing its passage in tissue culture.

\section{METHODS}

Viruses. The foamy virus strain investigated was isolated from a cynomolgus kidney culture by subculture to rabbit kidney tissue. A large pool was prepared by a further subculture into rabbit kidney tissue and stored at $-20^{\circ}$. SA1 was kindly supplied by Dr H. Malherbe, South African Institute for Medical Research, Johannesburg, and FV 21 by Dr P. Johnston of The Jefferson Medical College of Philadelphia. Several strains of SV 5 and MINIA which occurred spontaneously in kidney cultures of various monkey species formed the basis of observations made in this paper. 
Tissue cultures. Monolayer monkey kidney and rabbit kidney cultures were used, the initiating medium consisting of Earle's balanced salt solution, $0.5 \%$ lactalbumin hydrolysate, $2.5 \%$ calf serum ( $5 \%$ for rabbit cultures), $0.22 \%$ sodium bicarbonate and 100 units $/ \mathrm{ml}$. each of penicillin and streptomycin. The maintenance medium for monkey cultures was Earle's salt solution, $10 \%$ liver digest (Smith, 1961), $0.22 \%$ sodium bicarbonate, penicillin and streptomycin, and for rabbit cultures, Earle's salt solution, 5\% calf serum, $1 \%$ lactalbumin hydrolysate, $\mathbf{0 . 2 2} \%$ sodium bicarbonate, penicillin and streptomycin. Tube cultures were rolled at $37^{\circ}$.

Titrations. Serial dilutions of $0.5 \log _{10}$ steps were inoculated into rabbit or patas tube cultures, $0.5 \mathrm{ml}$. per tube. The cultures were examined microscopically after 7 or 8 days. Titres were deduced by the Kärber equation and are expressed as $\log _{10}$ TCID $50 / 0.5 \mathrm{ml}$.

Neutralization tests. Each of a series of doubling dilutions of serum was mixed with an equal volume of virus suspension (titre 2.5). After one and a half hr. incubation at $37^{\circ}$ each reaction mixture was inoculated into rabbit or patas tube cultures, $0.5 \mathrm{ml}$./tube, and examined 7 or 8 days later.

Diethyl ether sensitivity. Equal quantities of virus suspension and diethyl ether were shaken together and held at $4^{\circ}$ for $18 \mathrm{hr}$. The ether was evaporated under reduced pressure.

Size estimation by ultracentrifugation. A virus suspension was centrifuged for fifteen minutes in the SW 39 rotor at 39,000 r.p.m. (125,000 g) in a Spinco model L. The centrifuge tube contained $2.5 \mathrm{ml}$. of $3 \%$ agar, above which was $2.5 \mathrm{ml}$. virus suspension. Pre- and post-centrifugation samples were titrated.

Stability and heat sensitivity. One ml. volumes of foamy virus suspended in serumfree rabbit kidney tissue culture fluid clarified by centrifugation were sealed in $2 \mathrm{ml}$. glass ampoules and held at the appropriate temperatures. After exposure to $45^{\circ}$ or $50^{\circ}$ the ampoules were immediately cooled in ice water.

Haemagglutination and haemadsorption tests. Haemagglutination tests were done in plastic agglutination plates by mixing equal volumes of virus suspension and $\mathbf{0 . 2 5} \%$ suspensions of washed erythrocytes in veronal buffered saline, and incubating at the appropriate temperature. Tissue cultures showing cytopathic effect were tested for the haemadsorptive property by inoculating washed erythrocytes into the culture fluid to produce an approximately $0.5 \%$ suspension. The cultures were examined microscopically after allowing $1 \mathrm{hr}$. for the erythrocytes to settle onto the cell sheet.

Hyperimmune sera. An antiserum to the foamy virus was prepared in rabbits by a series of six intramuscular inoculations, the first consisting of $3 \mathrm{ml}$. of virus (titre 2.7) homogenized with an equal quantity of a mixture of nine parts oil (Esso grade 23, technical white) and one part sorbitan mono-oleate. Each of the remaining inocula was of $3 \mathrm{ml}$. of virus only. The measles antiserum was prepared in the same manner, the Edmonston strain of virus being used. The SA1 antiserum was provided by Dr H. Malherbe. 


\section{RESULTS}

\section{Comparison of the cytopathic effects of foamy virus, SV 5 and MINIA in monkey kidney cultures}

The 'spontaneous' occurrence of foamy virus in normal, uninoculated primary cultures was characterized by the formation of syncytia, which tended to be irregular in shape and contain clusters of nuclei. The lesions usually appeared 9-21 days following the preparation of the cultures. No inclusion bodies have been observed. Vacuolation of the syncytium usually took place producing the characteristic 'foamy' appearance. Plate 1, figs. 1, and 2, show the characteristic lesions unstained and stained by the haematoxylin eosin technique.

The presence of SV 5 in primary monkey kidney cultures has not usually produced a cytopathic effect. On subculture into monkey kidney culture a cytopathic effect could be produced, involving the formation of syncytia which soon lost their syncytial nature to become masses of cytoplasm containing small vacuoles and remains of nuclei (Pl. 2, fig. 3). The cytopathic effect was pronounced about 3 days following subculture.

In some tissue culture batches the cytopathic effect produced by foamy virus has been rather similar to that of SV 5. In such cases the foamy syncytia tended to roll up and leave a hole in the tissue sheet surrounded by 'spongy' masses of cytoplasm (Pl. 3, fig. 4). The lesions shown in Pl. 1, fig. 1, Pl. 3, fig. 4, were caused by the same strain of foamy virus; the tissue cultures, however, came from different rhesus monkeys.

Several isolates of MINIA, neutralizable by measles antiserum, were examined and found to have a cytopathic effect readily distinguishable from that of foamy virus. Spontaneous lesions in primary cultures took the form of rounded syncytia surrounded by swollen cells. The nuclei of a syncytium were arranged in a complete or broken ring, the cytoplasm within which was more refractile than that without (Pl. 4, fig. 5). Haematoxylin eosin staining showed a large eosinophilic inclusion body within each nucleus; the dense cytoplasm within the circle of nuclei was also eosinophilic (Pl. 4, fig. 6).

\section{Incidence of foamy virus in kidney tissue cultures of different monkey species}

The percentage of cultures, from four different monkey species, showing the foamy effect, together with the geographical region from which the monkeys originated, are shown in Table 1.

\section{Growth and transmission in tissue culture}

The growth of foamy virus in a Roux bottle rhesus kidney culture, inoculated with 50 TCID 50/0.5 ml. of culture fluid, was followed by titrating samples removed serially; the values are plotted in Fig. 1. At no stage following virus inoculation was the culture medium changed. The foamy cytopathic effect which appeared progressed to destroy the whole cell sheet. The virus titres reached in cultures experimentally infected with foamy virus have not been found to exceed $3 \cdot 5$.

The progress and spread of the cytopathic effect following experimental infection of a cell sheet was found to depend on the quantity of virus inoculated. The cytopathic effect produced by inocula of greater than about 5 to 10 TCID 50/tube culture usually progressed to destroy the cell sheet. If only one or a few TCID50 were 
inoculated a proportionately small number of lesions were formed, which did not spread or multiply in number. Both progressive and non-progressive effects could be observed in foamy virus titrations in monkey kidney cultures. Spontaneous foamy lesions which did not progress or multiply have been observed in primary monkey kidney cultures. It has not usually been possible, by subculture into rabbit or monkey kidney cultures, to detect foamy virus in cultures showing only a few non-progressive lesions.

The sensitivity of unaffected tissue in cultures containing only a few lesions to superinfection with foamy virus was investigated as follows. Patas kidney tube cultures were inoculated with foamy virus resulting in the development of about

\section{Table 1. Incidence of foamy virus in kidney cultures}

\section{Monkey \\ Region of origin \\ $\%$ of cultures foaming}

India

Thailand

Kenya and Somalia

Nigeria
$46 \%$ of 1615 cultures

$65 \%$ of 259 cultures

$40 \%$ of 65 cultures $0 \%$ of 296 cultures (vervet)

Erythrocebus patas (patas)

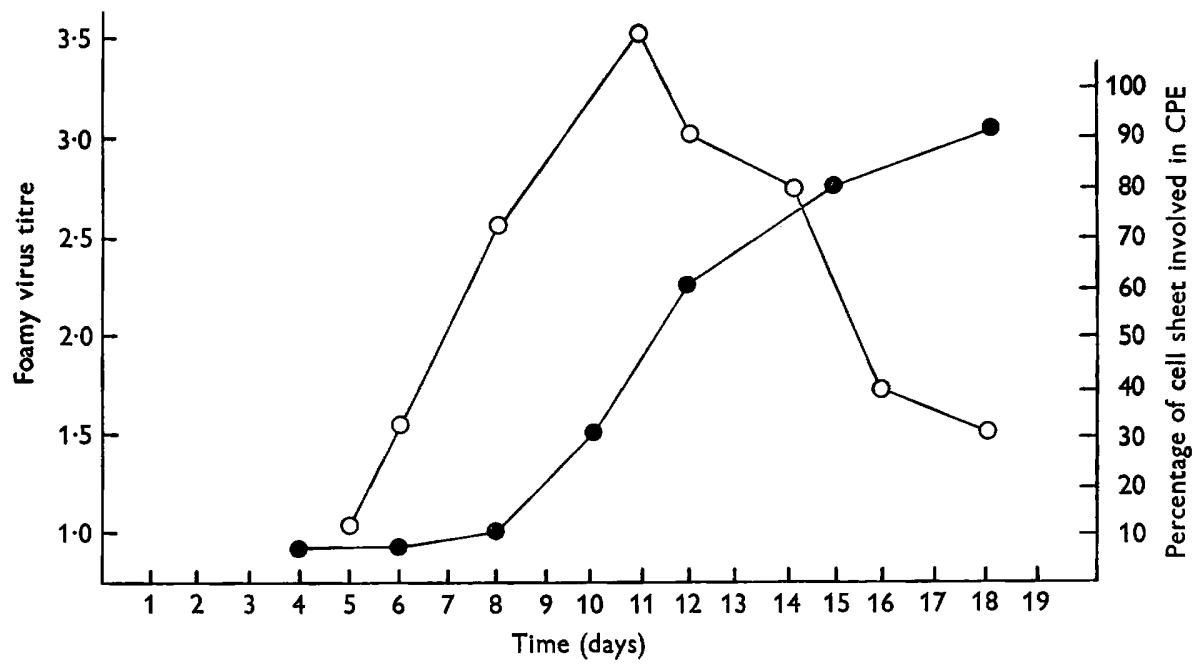

Fig. 1. Growth curve of foamy virus in rhesus kidney tissue. $O$, foamy virus titre;

, $\%$ of cell sheet invoved in cytopathic effect (CPE).

four foamy lesions per culture six days later. At the time of development of these lesions a third of the cultures was infected with a further 30 TCID50 per culture. Three days later another third of the cultures was similarly inoculated. Five days following the second superinfection all the cultures were examined. Those which had not been superinfected remained unchanged in appearance, having the same number of lesions as $\mathbf{8}$ days previously. All superinfected cultures showed a marked increase in the number of foamy lesions.

The readiness with which foamy virus could be subcultured was found to be dependent on the species of tissue cultures involved. The cytopathic effect produced by subculture from monkey kidney to monkey kidney was considerably less pronounced than that produced by either subculture from monkey kidney to rabbit 
kidney or rabbit kidney to monkey kidney. Whereas samples of foamy virus grown in monkey kidney cultures produced no cytopathic effect when titrated in the same tissue, titration in rabbit kidney cultures revealed titres of 2-5-3.0. The degree of cytopathic effect produced by subculturing from rabbit kidney to monkey kidney was found to vary with the species of monkey kidney involved. The most marked effects were obtained with kidney cultures from Erythrocebus patas.

\section{Antigenic relationship between foamy viruses}

A rabbit immune serum prepared against the cynomolgus foamy isolate described in this paper had a neutralization titre of 1/500-1/1000. The same titre was obtained against the SA1 virus of Malherbe \& Harwin (1957) and a type 1 foamy virus (FV 21) of Johnston (1961). Rabbit antiserum against SA1 neutralized both SA 1 and the cynomolgus foamy isolate to a titre of $1 / 50$. Foamy virus strains from five cynomolgus, six vervet and two rhesus kidney cultures were all neutralized by the antiserum against the cynomolgus isolate to the same titre as the homologous virus. These results indicate that all the above strains are antigenically similar and correspond to Johnston's serologic type 1.

\section{Physical properties}

Ether sensitivity. Eighteen hr. at $4^{\circ}$ treatment with diethyl ether reduced the titre from $2 \cdot 9$ to $<0 \cdot 5$. Treatment with chloroform and fluorocarbon $\left(\mathrm{Cl}_{3} \mathrm{~F}_{3} \mathrm{C}_{2}\right)$ under similar conditions also destroyed the viability.

Size. Ultracentrifugation $(125,000 \mathrm{~g}$ for $15 \mathrm{~min}$.) reduced the titre of a clarified culture fluid suspension from $2 \cdot 75$ to $1 \cdot 5$. Concentration of foamy virus suspensions at higher speeds indicated that the viability is not destroyed or reduced by ultracentrifugation, the increase in titre of the pellet corresponding to the reduction in titre of the supernatant. Comparison of these results with the sedimentation behaviour of other viruses in the swinging bucket rotor of the Spinco ultracentrifuge indicates a particle diameter of greater than $70 \mathrm{~m} \mu$. This conclusion is only valid if foamy virus is non-filamentous, and has a hydrated particle density similar to other viruses. Attempts to study the particle by electron microscopy of phosphotungstate negatively contrasted concentrates were not successful due to the difficulty in obtaining satisfactory concentrates from a virus producing such low titres in tissue culture fluids.

Stability and heat sensitivity. The stability at various temperatures is summarized in Table 2.

Haemagglutination and haemadsorption. No haemagglutination or haemadsorption could be detected at $4^{\circ}, 22^{\circ}$ or $37^{\circ}$, using erythrocytes from the following animals : rhesus, cynomolgus, vervet, patas, Sykes and Papio monkeys, human, horse, dog, cat, ferret, rat, rabbit, guinea pig or chicken. Concentrated foamy virus with a titre of 5.0 did not agglutinate guinea pig erythrocytes at $4^{\circ}, 22^{\circ}$ or $37^{\circ}$.

\section{DISCUSSION}

The freedom of Erythrocebus patas kidney cultures from spontaneous foamy virus, and the clarity of the cytopathic effect produced by the inoculation into such cultures of foamy virus grown in rabbit tissue, considerably facilitated the study of this virus. 
The difficulties that are associated with the subculture and transmission of foamy virus, particularly in monkey kidney cultures, may be explained by the observations made in this paper. The growth curve demonstrates that low titres only are

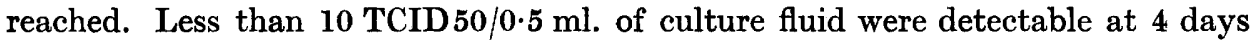
following experimental inoculation, even though a clear cytopathic effect had appeared. The decrease in titre following the maximum of 3.5 probably resulted from less virus being released from the tissue combined with the relative lability of the virus at $37^{\circ}$ (Table 2). Fluid subcultured early or late from such a foamy infected tissue would contain only a small number of tissue infective doses.

The small, isolated foamy lesions occurring in monkey cultures, either spontaneously or from experimental infection, have usually been non-progressive, the major part of the cell sheet remaining unaffected, even though its sensitivity to superinfection by foamy virus was retained. This lack of spread is apparently due to

Table 2. Stability at various temperatures of foamy virus suspended in a serum-free medium

Titre at commencement

Temperature of experiment

Titre after time intervals indicated below

$-20^{\circ}$
$4^{\circ}$
$22^{\circ}$
$37^{\circ}$
$45^{\circ}$
$50^{\circ}$

\begin{tabular}{l}
2.75 \\
$2 \cdot 75$ \\
$2 \cdot 5$ \\
$2 \cdot 75$ \\
2.75 \\
$2 \cdot 0$ \\
\hline
\end{tabular}

\begin{tabular}{|c|c|c|c|c|c|c|c|c|}
\hline $2 \cdot 75$ & $2 \cdot 5$ & $2 \cdot 25$ & $2 \cdot 0$ & 1.75 & 1.5 & $1 \cdot 25$ & $1 \cdot 0$ & $<1.0$ \\
\hline $\begin{array}{c}48 \\
\text { weeks }\end{array}$ & - & - & - & - & - & - & - & - \\
\hline- & - & $\begin{array}{c}12 \\
\text { weeks }\end{array}$ & - & $\begin{array}{c}\mathbf{2 0} \\
\text { weeks }\end{array}$ & - & - & - & $\begin{array}{c}29 \\
\text { weeks }\end{array}$ \\
\hline- & - & $\begin{array}{c}4 \\
\text { days }\end{array}$ & $\begin{array}{c}6 \\
\text { days }\end{array}$ & $\begin{array}{c}8 \\
\text { days }\end{array}$ & - & - & - & - \\
\hline- & - & $\begin{array}{c}1 \\
\text { day }\end{array}$ & - & $\begin{array}{c}2 \\
\text { days }\end{array}$ & - & - & - & $\begin{array}{c}3 \\
\text { days }\end{array}$ \\
\hline - & - & - & $\begin{array}{c}15 \\
\text { min. }\end{array}$ & $\begin{array}{c}\mathbf{3 0} \\
\text { min. }\end{array}$ & - & $\begin{array}{c}\mathbf{4 0} \\
\text { min. }\end{array}$ & $\begin{array}{c}60 \\
\text { min. }\end{array}$ & $\begin{array}{c}90 \\
\text { min. }\end{array}$ \\
\hline
\end{tabular}

less than one TCID50 being released into the culture fluid. 'Auto-inhibition' probably does not occur for, although it is sensitive to interferon, foamy virus does not stimulate interferon production (Plummer, to be published).

The poor development, or complete absence, of the lesions when subculturing from monkey tissue to monkey tissue, undoubtedly contributes significantly to the difficulties of tissue culture passage. Added to this is the resistance to foamy virus of any cultures containing SV 5, due to the production of interferon by SV 5 and the sensitivity to interferon of foamy virus (Plummer, to be published). This emphasizes the necessity for screening by the haemadsorption technique all monkey kidney cultures to be used for passaging foamy virus, particularly in view of the presence of SV 5 in primary cultures frequently being unaccompanied by a cytopathic effect.

Classification of the virus is not yet possible. However, it can be excluded from the ether resistant groups, and lack of inclusion bodies excludes it from the 'nitaviruses' (Andrews et al. 1961). It cannot be placed amongst the Myxoviruses if haemagglutination is to remain a criterion for inclusion in this group. Work on the structure of the virus clearly needs to be done to assist in its classification. 


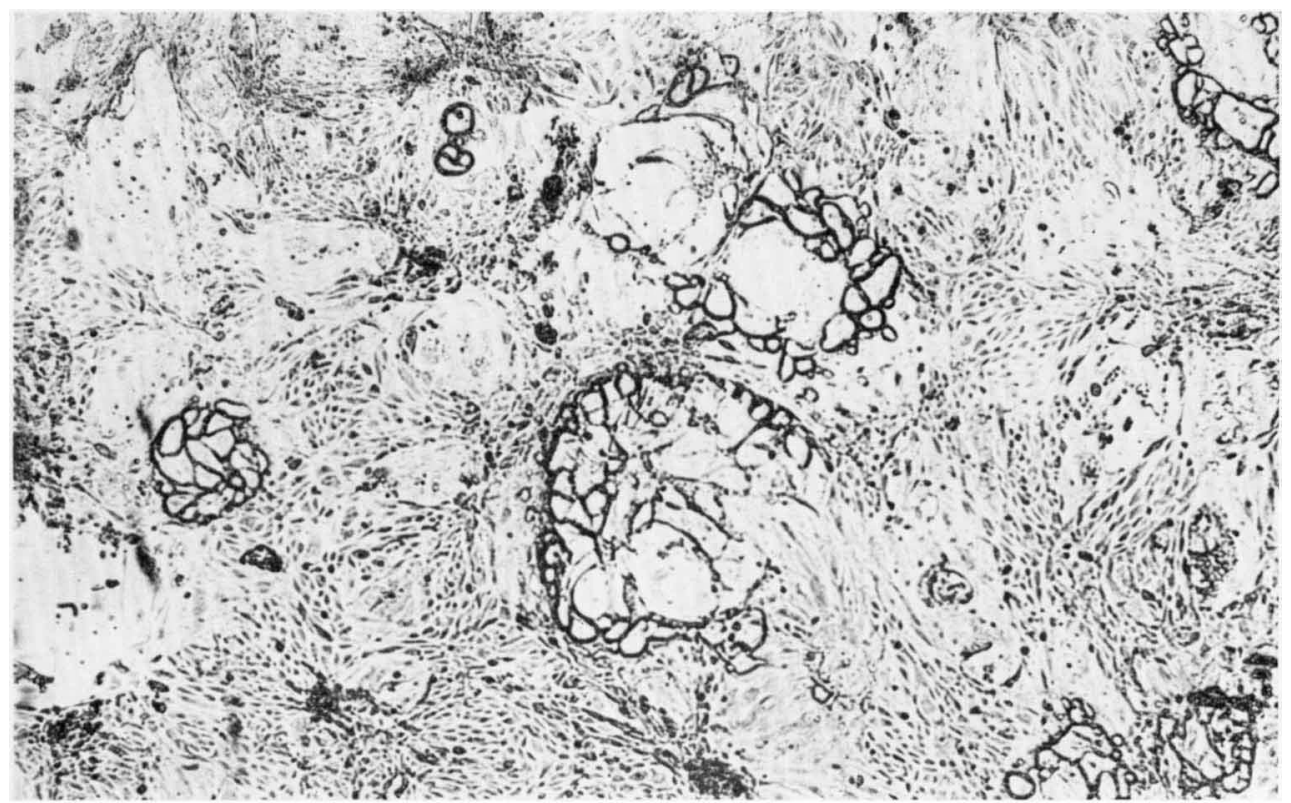

Fig. 1

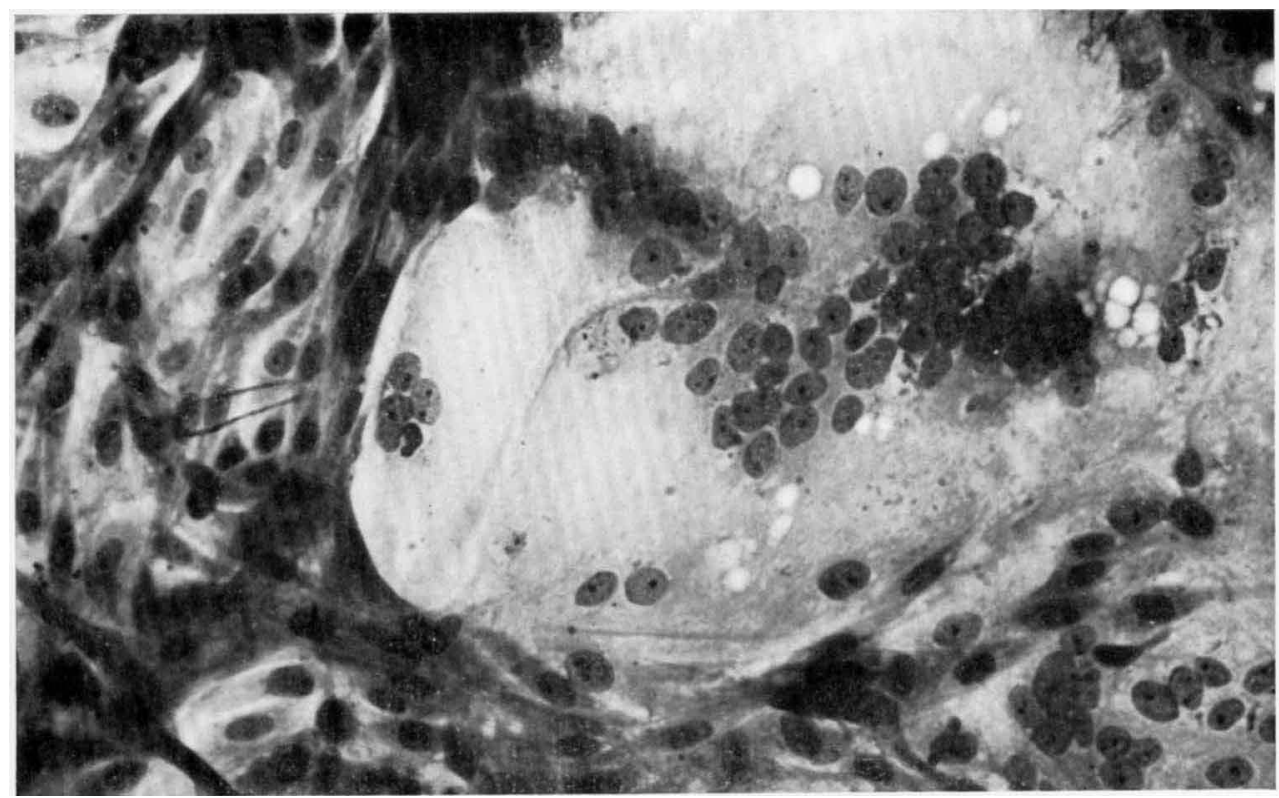

Fig. 2 


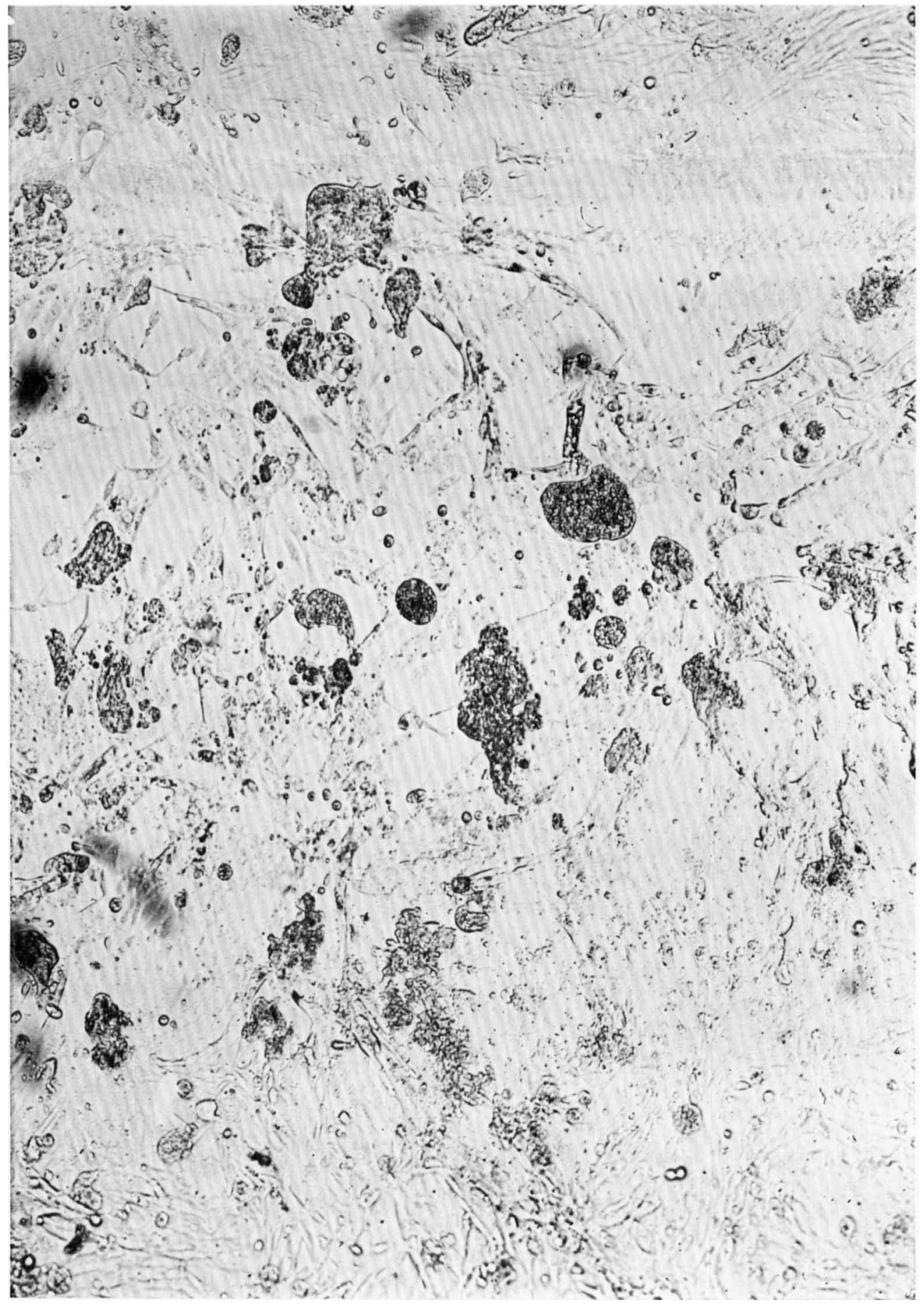

G. PLUMMER

Fig. 3 


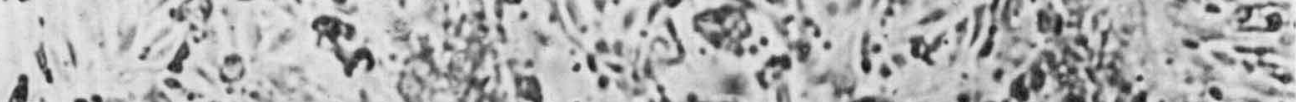
2.

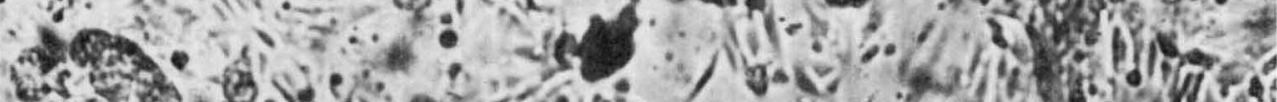

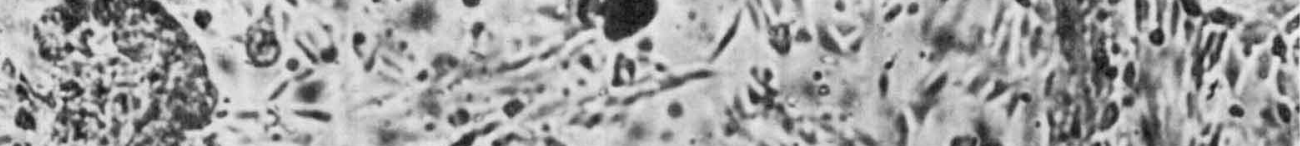
of

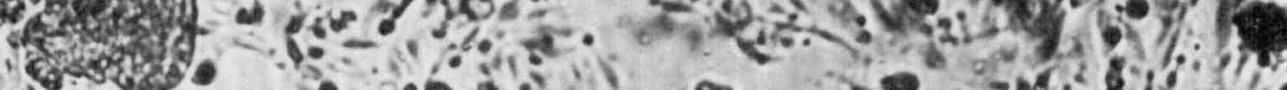

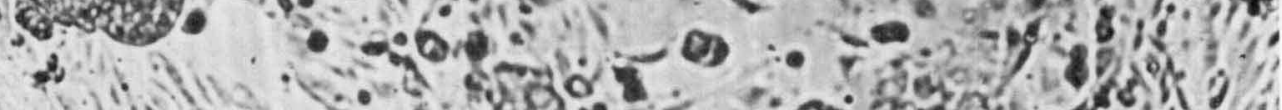

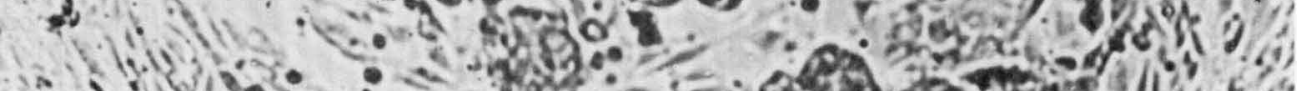

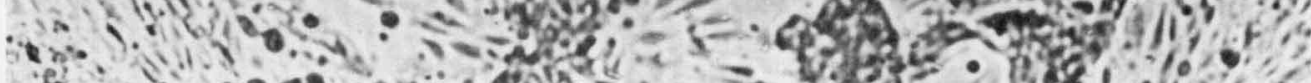

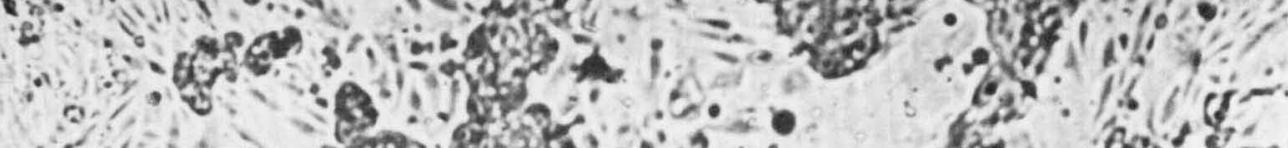

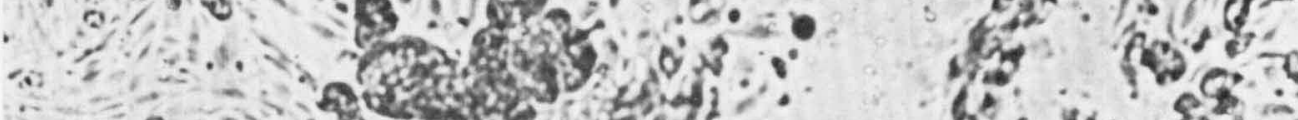

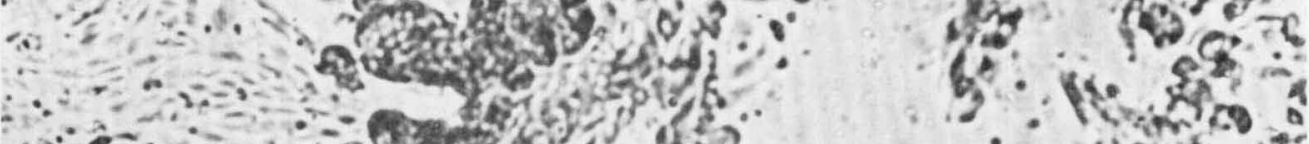

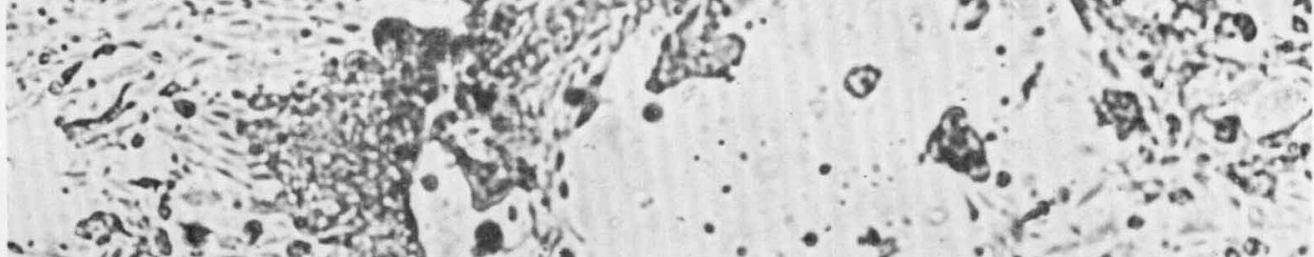

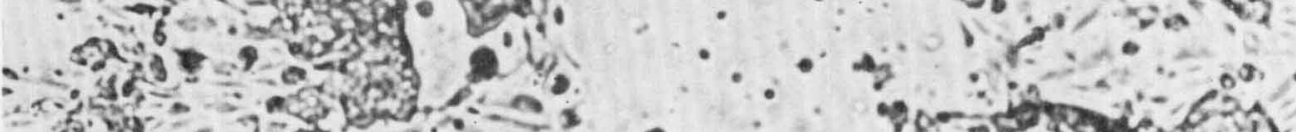

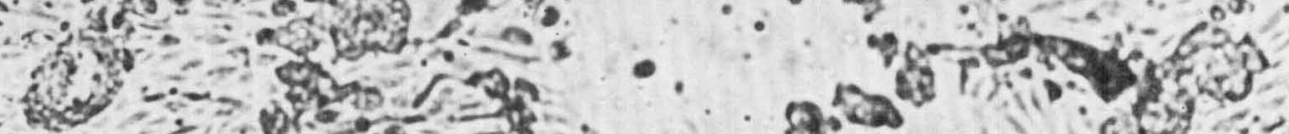

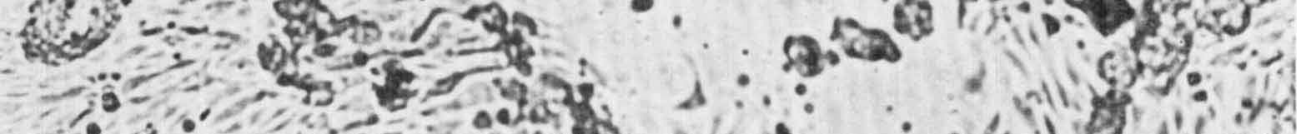

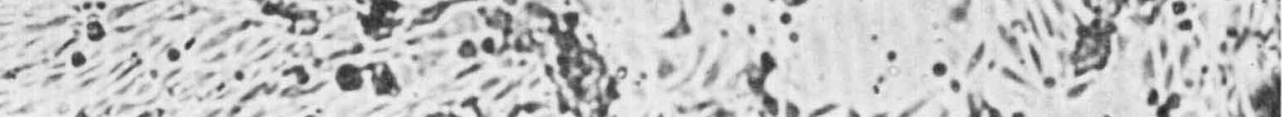

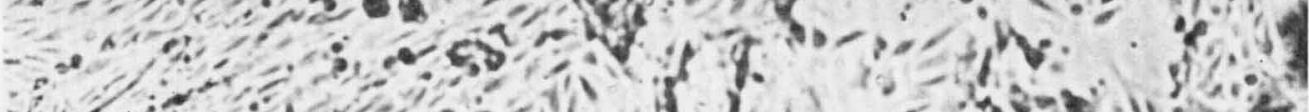

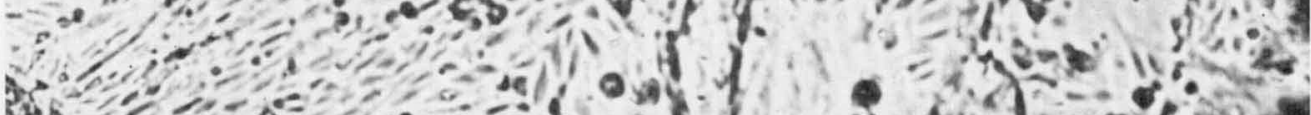

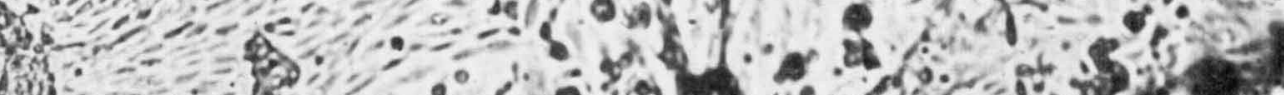

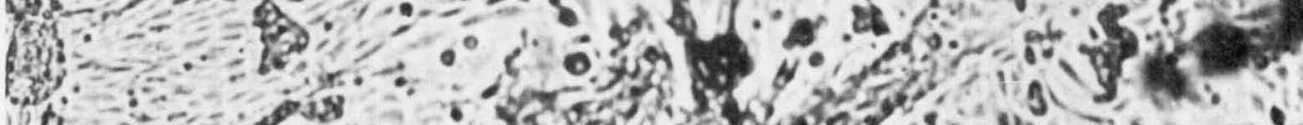
t. B

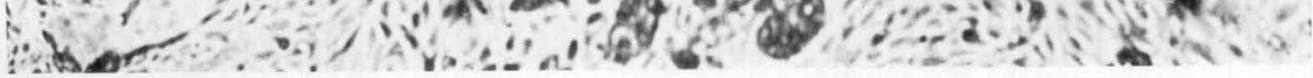




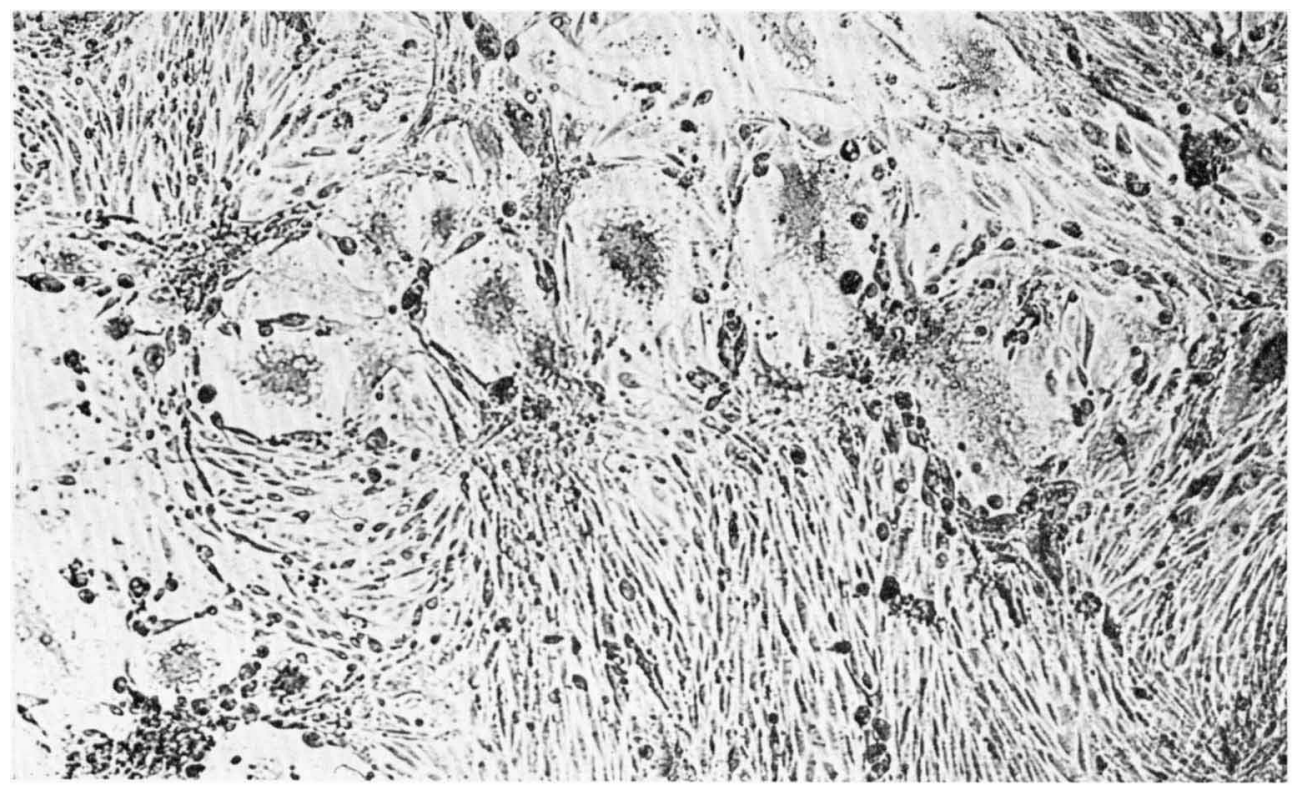

Fig. 5

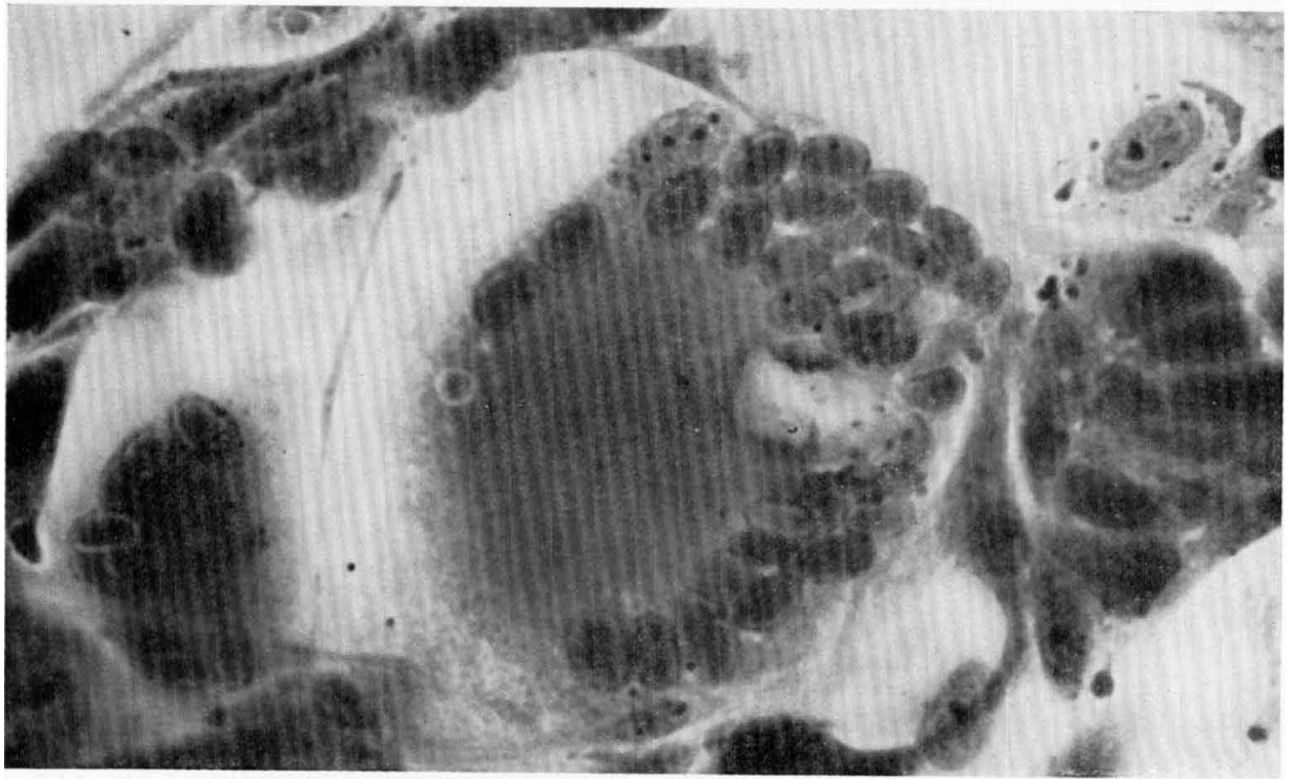

G. PLUMMER

Fig. 6 


\section{REFERENCES}

Andrewes, C. H., Burnet, F. M., Enders, J. S., Gard, S., Hirst, G. K., Kaplan, M. M. \& Zhdanov, V. M. (1961). Taxonomy of viruses infecting vertebrates: present knowledge and ignorance. Virology, $15,52$.

Brown, L. V. (1957). Pathogenicity for rabbit kidney cell cultures of certain agents derived from normal monkey kidney tissue. I. Isolation and propagation. Amer. J. Hyg. 65, 189.

HulL, R. N. \& MrNner, J. R. (1957). New viral agents recovered from tissue cultures of monkey kidney cells. II. Problems of isolation and identification. Ann. N.Y. Acad. Sci. 67, 413.

Johnston, P. B. (1961). A second immunologic type of simian foamy virus: monkey throat infections and unmasking of both types. J. infect. Dis. 109, 1.

MaLherbe, H. \& Harwin, R. (1957). Seven viruses isolated from the vervet monkey. Brit. J. exp. Path. 28, 539.

RuckIE, G. (1958). Studies with the Monkey-Intra-Nuclear-Inclusion-Agent (MINIA) and Foamy Agent, I, II. Archiv. ges. Virusforsch. 8, 139, 167.

Rustigian, R., Johnston, P. B. \& Reihart, H. (1955). Infection of monkey kidney tissue cultures with virus-like agents. Proc. Soc. exp. Biol., N.Y. 88, 8.

Sмrтн, S. E. (1961). A maintenance medium for tissue culture virus studies. Brit. J. exp. Path. 42, 232.

\section{EXPLANATION OF PLATES}

Plate 1

Fig. 1. Foamy lesions in an unstained rhesus kidney culture. $\times \mathbf{4 6}$.

Fig. 2. Foamy lesion stained with haematoxylin eosin following fixation with Bouin's fluid. $\times 330$.

\section{Plate 2}

Fig. 3. SV5 lesions in an unstained rhesus kidney culture. $\times 160$.

Plate 3

Fig. 4. Foamy lesion in an unstained rhesus kidney culture. $\times 120$.

\section{Plate 4}

Fig. 5. MINIA lesions in an unstained rhesus kidney culture. $\times 80$.

Fig. 6. MINIA lesion stained with haematoxylin eosin following fixation with Bouin's fluid. $\times 495$. 